\title{
Community Rehabilitation for Acquired Brain Injury
}

$\mathrm{T}$ raditionally, neurological rehabilitation has been conceptualised within the medical model and this has had a decidedly inpatient, hospital-based orientation. There are a number of clinical services developed 30 or more years ago, however, which are exceptions, and they highlight the need for a continuum, and even a lifetime, of services and supports. One example is the model system initiated by Dr Sheldon Berrol at Santa Clara Valley, United States of America and, on the local scene, the service established by Professor Tony Broe in Sydney at Lidcombe (later relocated to Liverpool) Hospital.

There are a number of converging reasons why neurological rehabilitation services and supports need to extend beyond a hospital-based, inpatient focus. The first of these comes from the medical model itself. The revised World Health Organization model, the International Classification of Functioning, Disability and Health (1980, 2001), recognises that outcome and community participation are not only a matter of impairments and activity limitations, but also that contextual factors play a crucial role. Contextual factors, both environmental and personal, may cause barriers or alternatively exert facilitating effects. As such, contextual factors take many forms, including social support, financial security and emotional wellbeing. This greater emphasis on a social model of medicine sits comfortably with the rehabilitation scene.

Moreover, in previous issues of this journal, Ylvisaker $(2000,2003)$ has argued persuasively for contextually-based rehabilitation. Yet, it is well nigh impossible to conduct contextually-relevant rehabilitation within the confines of an inpatient rehabilitation unit. This is not to suggest that inpatient rehabilitation units are not of fundamental importance in the rehabilitation process; rather, that rehabilitation should not end when the patient is discharged home. Indeed, as we have argued elsewhere (Tate, Strettles, \& Osoteo, 2003), the time period following post-acute rehabilitation is precisely when patients (and families) are best placed and exhibit a readiness to deal with cognitive and behavioural impairments. The risk is, however, that once patients are discharged from inpatient rehabilitation units they do not receive any active rehabilitation at all.

Related to the foregoing, it is recognised that the majority of people with severe acquired brain injury are not fully recovered when they are discharged from inpatient rehabilitation services. Even though some individuals may show ongoing improvement over subsequent years, the fact is that residual disablement can last a lifetime. As an illustration, our group has followed up a consecutive series of 100 people with severe traumatic brain injury (TBI) at 20-26 years posttrauma. One focus of this study was long-term support needs (Tate, Strettles, Hodgkinson, \& Veerabangsa, 2003). In this very longterm cohort, a huge percentage $(85 \%)$ had used at least one service related to their TBI in the previous 12 months and $72 \%$ were assessed as having ongoing support needs in areas such as work, social participation, respite accommodation, domestic support, financial management and transport. In spite of the high support needs, virtually all individuals (95.5\%) were living in the community, often due to Herculean efforts by family members. Needs for 
community rehabilitation services and supports wax and wane over the lifespan, as does the configuration of these needs in accordance with life events (e.g., illness of a family carer, retrenchment from work, effects of the ageing process). This calls for flexible systems characterised by a needs-driven, individually-based focus. Supporting people with brain impairment to live in the community must be a fundamental public health objective, but the challenge is to maintain and further develop community supports and community-based rehabilitation services.

This special issue of Brain Impairment furthers this objective by presenting an integrated set of seven papers by Australian authors pertinent to community rehabilitation after acquired brain injury. A number of the papers were platform presentations or workshops at the 2003 ASSBI conference. The papers in this issue represent a mix of qualitative and quantitative methodology, professional disciplines and geographical locations. The first paper, by Foster, is not, in fact, about community per se, but its relevance lies in its topic of decision-making in the referral process and equity of access to services. This is a thought-provoking, challenging paper and many of the principles that Foster identified in the acute setting apply equally to the community and thus it sets the context well for the following papers. Foster's paper is followed by that authored by Sloan, Winkler and Callaway, who describe the model of community rehabilitation practice they developed, which is characterised by an individualised and collaborative approach to community participation. Specific issues that have particular currency in community rehabilitation are addressed in papers by Kuipers, Carlson, Bailey, and Sharma (goal setting), Todd, Loewy, Kelly, and Simpson (challenging behaviours), and Ownsworth, Crabtree, Carlson and Brennan (clients' perspectives of service provision). Simpson, Secheny, Lane-Brown, Strettles, Ferry, and Phillips evaluate outcomes from a transitional living program, and the final paper by Tate, Strettles, and Osoteo examines patterns of service utilisation in a consecutive series of clients of a brain injury community service. Taken together, these papers provide an overview of some diverse issues pertinent to community rehabilitation for acquired brain injury.

\section{References}

Tate, R.L., Strettles, B., Hodgkinson, A.E. \& Veerabangsa, A. (May, 2003). Long-term support needs after traumatic brain injury. Report to the Motor Accidents Authority of New South Wales.

Tate, R.L., Strettles, B., \& Osoteo, T. (2003). Enhancing outcomes after traumatic brain injury: A social rehabilitation approach. In: B.A. Wilson (Ed.), Neuropsychological rehabilitation: Theory and practice (pp. 137-169). Lisse, The Netherlands: Swets \& Zeitlinger.

World Health Organization (WHO) (1980). The international classification of impairments, disabilities and handicaps (ICIDH). Geneva: Author.

World Health Organization (WHO) (2001). The international classification of functioning, disability and health (ICF). Geneva: Author.

Ylvisaker, M. (2003). Context-sensitive cognitive rehabilitation after brain injury: Theory and practice. Brain Impairment, 4, 1-16.

Ylvisaker, M., \& Feeney, T. (2000). Reconstruction identity after brain injury. Brain Impairment, 1, 12-28.

\footnotetext{
Robyn Tate PhD

Rehabilitation Studies Unit, Faculty of Medicine, University of Sydney, and Royal Rehabilitation Centre Sydney
} 